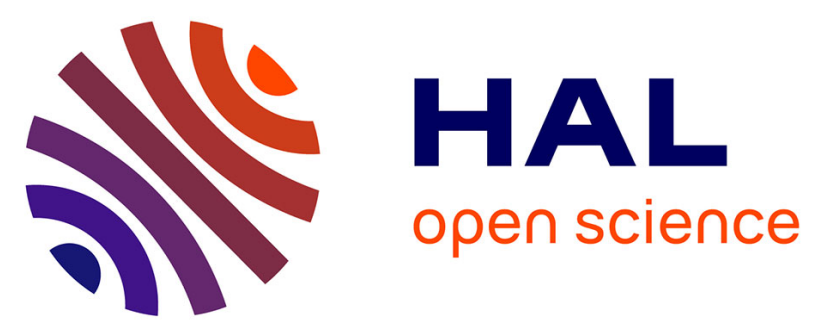

\title{
French validation of the questionnaire for Impulsive-Compulsive Disorders in Parkinson's Disease-Rating Scale (QUIP-RS)
}

Ana Marques, Tiphaine Vidal, Bruno Pereira, Eve Benchetrit, Julie Socha, Fanny Pineau, Alexis Elbaz, Fanny Artaud, Graziella Mangone, Hana You, et al.

\section{To cite this version:}

Ana Marques, Tiphaine Vidal, Bruno Pereira, Eve Benchetrit, Julie Socha, et al.. French validation of the questionnaire for Impulsive-Compulsive Disorders in Parkinson's Disease-Rating Scale (QUIPRS). Parkinsonism \& Related Disorders, 2019, 10.1016/j.parkreldis.2019.02.026 . hal-02111588

\author{
HAL Id: hal-02111588 \\ https://hal.uca.fr/hal-02111588
}

Submitted on 25 Oct 2021

HAL is a multi-disciplinary open access archive for the deposit and dissemination of scientific research documents, whether they are published or not. The documents may come from teaching and research institutions in France or abroad, or from public or private research centers.
L'archive ouverte pluridisciplinaire HAL, est destinée au dépôt et à la diffusion de documents scientifiques de niveau recherche, publiés ou non, émanant des établissements d'enseignement et de recherche français ou étrangers, des laboratoires publics ou privés.

\section{(ㅇ)(1) $\$$}

Distributed under a Creative Commons Attribution - NonCommerciall 4.0 International 


\section{French validation of the Questionnaire for Impulsive-Compulsive Disorders in Parkinson's Disease-Rating Scale (QUIP-RS)}

Ana MARQUES ${ }^{1}$, Tiphaine VIDAL ${ }^{1}$, Bruno PEREIRA ${ }^{2}$, Eve BENCHETRIT ${ }^{3}$, Julie SOCHA ${ }^{3}$, Fanny PINEAU ${ }^{3}$, Alexis ELBAZ4, Fanny ARTAUD ${ }^{4}$, Graziella MANGONE ${ }^{3}$, Hana YOU ${ }^{3}$, Florence CORMIER ${ }^{3}$, Monique GALITSTKY ${ }^{5}$, Elsa POMIES ${ }^{5}$, Olivier RASCOL ${ }^{5}$, Pascal DERKINDEREN ${ }^{6}$, Daniel WEINTRAUB ${ }^{7}$, Jean Christophe CORVOL $^{3}$, Franck DURIF ${ }^{1}$ and the DIGPD study group

1. Université Clermont Auvergne, NPsy-Sydo, CHRU Clermont-Ferrand, Neurology Department, Clermont-Ferrand, France

2. CHRU Clermont-Ferrand, Délégation à la Recherche Clinique et Informatique, ClermontFerrand, France

3. Sorbonne Université, INSERM, CNRS, Assistance Publique Hôpitaux de Paris, Institut du Cerveau et de la Moelle, Pitié-Salpêtrière Hospital, Department of Neurology, Paris, France

4. Université Paris-Saclay, Univ. Paris-Sud, UVSQ, CESP, INSERM, Villejuif, France

5. Université de Toulouse, $\mathrm{CHU}$ de Toulouse, INSERM; Centre d'Investigations Cliniques CIC1436, Centre Expert Parkinson, NS-Park/F-CRIN Network, Departments of Neurosciences and Clinical Pharmacology, Centre COEN NeuroToul. Toulouse, France

6. Université de Nantes, INSERM U913, CHRU Nantes Neurology department, Nantes, France

7.Departments of Psychiatry and Neurology, University of Pennsylvania School of Medicine, Philadelphia, PA, USA; Parkinson's Disease and Mental Illness Research, Education and Clinical Centers (PADRECC and MIRECC), Philadelphia Veterans Affairs Medical Center, Philadelphia, PA, USA

\section{DIGPD Study group}

Steering committee: Jean-Christophe Corvol, MD, PhD (Pitié-Salpêtrière Hospital, Paris, principal investigator of DIGPD), Alexis Elbaz, MD, PhD (CESP, Villejuif, member of the steering committee), Marie Vidailhet, MD (Pitié-Salpêtrière Hospital, Paris, member of the steering 
committee), Alexis Brice, MD (Pitié-Salpêtrière Hospital, Paris, member of the steering committee and PI for genetic analysis) ;

Statistical analyses: Alexis Elbaz, MD, PhD (CESP, Villejuif, PI for statistical analyses), Fanny Artaud, PhD (CESP, Villejuif, statistician);

Principal investigators for sites (alphabetical order): Frédéric Bourdain, MD ( $\mathrm{CH}$ Foch, Suresnes, PI for site), Jean-Philippe Brandel, MD (Fondation Rothschild, Paris, PI for site), JeanChristophe Corvol, MD, PhD (Pitié-Salpêtrière Hospital, Paris, PI for site), Pascal Derkinderen, MD, PhD (CHU Nantes, PI for site), Franck Durif, MD (CHU Clermont-Ferrand, PI for site), Richard Levy, MD, PhD (CHU Saint-Antoine, Paris, PI for site), Fernando Pico, MD (CH Versailles, PI for site), Olivier Rascol, MD (CHU Toulouse, PI for site);

Co-investigators (alphabtical order): Anne-Marie Bonnet, MD (Pitié-Salpêtrière Hospital, Paris, site investigator), Cecilia Bonnet, MD, PhD (Pitié-Salpêtrière Hospital, Paris, site investigator), Christine Brefel-Courbon, MD (CHU Toulouse, site investigator), Florence Cormier-Dequaire, MD (Pitié-Salpêtrière Hospital, Paris, site investigator), Bertrand Degos, MD, PhD (PitiéSalpêtrière Hospital, site investigator), Bérangère Debilly, MD (CHU Clermont-Ferrand, site investigator), Alexis Elbaz, MD, PhD (Pitié-Salpêtrière Hospital, Paris, site investigator), Monique Galitsky (CHU de Toulouse, site investigator), David Grabli, MD, PhD (Pitié-Salpêtrière Hospital, Paris, site investigator), Andreas Hartmann, MD, PhD (Pitié-Salpêtrière Hospital, Paris, site investigator), Stephan Klebe, MD (Pitié-Salpêtrière Hospital, Paris, site investigator), Julia Kraemmer, MD (Pitié-Salpêtrière Hospital, site investigator), Lucette Lacomblez, MD (PitiéSalpêtrière Hospital, Paris, site investigator), Sara Leder, MD (Pitié-Salpêtrière Hospital, Paris, site investigator), Graziella Mangone, MD, PhD (Pitié-Salpêtrière Hospital, Paris, site investigator), Louise-Laure Mariani, MD (Pitié-Salpêtrière Hospital, Paris, site investigator), Ana-Raquel Marques, MD (CHU Clermont Ferrand, site investigator), Valérie Mesnage, MD (CHU Saint Antoine, Paris, site investigator), Julia Muellner, MD (Pitié-Salpêtrière Hospital, Paris, site investigator), Fabienne Ory-Magne, MD (CHU Toulouse, site investigator), Violaine Planté-Bordeneuve, MD (Henri Mondor Hospital, Créteil, site investigator), Emmanuel Roze, MD, PhD (Pitié-Salpêtrière Hospital, Paris, site investigator), Melissa Tir, MD (CH Versailles, site investigator), Marie Vidailhet, MD (Pitié-Salpêtrière Hospital, Paris, site investigator), Hana You, MD (Pitié-Salpêtrière Hospital, Paris, site investigator);

Neuropsychologists: Eve Benchetrit, MS (Pitié-Salpêtrière Hospital, Paris, neuropsychologist), Julie Socha, MS (Pitié-Salpêtrière Hospital, Paris, neuropsychologist), Fanny Pineau, MS (PitiéSalpêtrière Hospital, Paris, neuropsychologist), Tiphaine Vidal, MS (CHU Clermont-Ferrand, neuropsychologist), Elsa Pomies ( $\mathrm{CHU}$ de Toulouse, neuropsychologist), Virginie Bayet (CHU de Toulouse, neuropsychologist);

Genetic core: Alexis Brice (Pitié-Salpêtrière Hospital, Paris, PI for genetic studies), Suzanne Lesage, PhD (INSERM, ICM, Paris, genetic analyses), Khadija Tahiri, PhD (INSERM, ICM, Paris, lab technician) Hélène Bertrand, MS (INSERM, ICM, Paris, lab technician), Graziella Mangone, $\mathrm{MD}, \mathrm{PhD}$ (Pitié-Salpêtrière Hospital, Paris, genetic analyses);

Sponsor activities and clinical research assistants: Alain Mallet, PhD (Pitié-Salpêtrière Hospital, Paris, sponsor representative), Coralie Villeret (Hôpital Saint Louis, Paris, Project manager), Merry Mazmanian (Pitié-Salpêtrière Hospital, Paris, project manager), Hakima Manseur (Pitié-Salpêtrière Hospital, Paris, clinical research assistant), Mostafa Hajji (PitiéSalpêtrière Hospital, Paris, data manager), Benjamin Le Toullec, MS (Pitié-Salpêtrière Hospital, Paris, clinical research assistant), Vanessa Brochard, PhD (Pitié-Salpêtrière Hospital, Paris, project manager), Monica Roy, MS (CHU de Nantes, clinical researh assistant), Isabelle Rieu, $\mathrm{PhD}$ (CHU Clermont-Ferrand, clinical research assistant), Stéphane Bernard (CHU ClermontFerrand, clinical research assistant), Antoine Faurie-Grepon ( $\mathrm{CHU}$ de Toulouse, clnical research assistant). 
Corresponding Author: A. Marques

Service de Neurologie, CHRU Gabriel Montpied

Place Henri Dunant, 63000 Clermont-Ferrand Cedex, FRANCE

$+33(0) 473751600$

ar_marques@chu-clermontferrand.fr

Authors: $\quad$ tvidal@chu-clermontferrand.fr; $\quad$ bpereira@chu-clermontferrand.fr; eve.benchetrit@aphp.fr; Julie.socha@aphp.fr; fanny.pineau@aphp.fr; alexis.elbaz@inserm.fr; fanny.artaud@inserm.fr; graziella.mangone@aphp.fr; hana.you@aphp.fr; Florence.cormier@aphp.fr; monique.galitzky@inserm.fr; elsa.pomies@univ-tlse3.fr; Olivier.rascol@univ-tlse3.fr; pascal.derkinderen@chu-nantes.fr; daniel.weintraub@uphs.upenn.edu;_ jean-christophe.corvol@aphp.fr; fdurif@chuclermontferrand.fr

Title Character count: 119

Number of references: 30

Number of tables: 3

Number of figures: 1

Number of supplemental tables: 3

Word count abstract: 247

Word count paper: 2837

Running title: French validation of QUIP-RS

Key words: Impulse Control Disorder; Parkinson disease; Validation; Rating Scale; Translation; French

Registration number: clinicaltrials.gov number NCT01564992

\section{Funding sources:}

The DIGPD cohort was sponsored by the Assistance Publique Hôpitaux de Paris, and funded by a grant from the French Ministry of Health (Programme Hospitalier de Recherche Clinique, AOR0810) and from the French Drug Agency (Agence Nationale de Sécurité et des 
Médicaments, ANSM-2013). The research leading to these results has received funding from the program "Investissements d'Avenir" ANR-10-IAIHU-06.

\section{Author Disclosures:}

Ana Marques: -reports non-financial support from Aguettant, grants from Elivie, grants and non-financial support from Orkyn, non-financial support from Abbvie, non-financial support from Merz, non-financial support from Saint Jude, outside the submitted work.

Tiphaine Vidal: -reports no disclosure

Bruno Pereira: -reports no disclosure

Eve Benchetrit:-reports no disclosure

Julie Socha: -reports no disclosure

Fanny Pineau: -reports no disclosure

Alexis Elbaz: reports research support from Agence nationale de la recherche (France) - IGEMP (2010-2012, PI) - Agence nationale de sécurité du médicament et des produits de santé (France)(BEAD-PD, 2014-2016, co-investigator) - JPND (Joint Programme - Neurodegenerative Disease Research, European research projects for the identification of genetic, epigenetic and environmental risk and protective factors for Neurodegenerative Diseases) (Courage-PD, 20142016, PI WP2) - Institut de santé publique (IRESP, France). Health behaviours and aging: longitudinal analysis of three cohort studies (2011-2013, co-investigator) - Institut de santé publique (IRESP, France). Risk of stroke and hormone therapy for menopause: the role of estrogens and progestogens (PRESSTO, 2012-2014, co-investigator). - agence nationale de la recherche $(A N R)=$ Decipher-PD; epigenetics in PD (2016-2018) - plan ecophyto from the French ministry of agriculture : PhD grant for a student working on agricultural characteristics and Parkinson's disease - Anses (government agency for food and environment safety) : solvents and motor function outside of the submitted work 
Fanny Artaud: -reports no disclosure

Graziella Mangone: -reports no disclosure

Hana You: -reports no disclosure

Florence Cormier: -reports no disclosure

Monique Galitzky: -reports no disclosure

Elsa Pomies: -reports no disclosure

Olivier Rascol:-reports honoraria for consultancy from AbbVie, Adamas, Acorda, Addex, AlzProtect, Apopharma, Astrazeneca, Bial, Biogen, Britannia, Clevexel, INC Reasearch, Lundbeck, Lupin, Merck, MundiPharma, Neuratris, Neuroderm, Novartis, Osmotica, Oxford Biomedica, Parexel, Pfizer, Prexton Therapeutics, Quintiles, Sanofi, Servier, Sunovion, Théranexus, Takeda, Teva, UCB, XenoPort, Zambon; grants from Agence Nationale de la Recherche (ANR), CHU de Toulouse, France-Parkinson, INSERM-DHOS Recherche Clinique Translationnelle, MJFox Foundation, Programme Hospitalier de Recherche Clinique, European Commission (FP7, H2020) outside the submitted work.

Pascal Derkinderen: -reports no disclosure.

Daniel Weintraub: -reports research funding or support from Michael J. Fox Foundation for Parkinson's Research, National Institutes of Health (NINDS), Novartis Pharmaceuticals, Department of Veterans Affairs, Avid Radiopharmaceuticals, Alzheimer's Therapeutic Research Initiative, Alzheimer's Disease Cooperative Study, and the International Parkinson and Movement Disorder Society; honoraria for consultancy from Acadia, Alkahest, Anavex Life Sciences, Biogen, Biotie (Acorda), BlackThorn Therapeutics, Bracket, Clintrex LLC, Eisai Inc., Eli Lilly, Jazz Pharma, Lundbeck, Roche, Sunovion, Takeda, Theravance Biopharma, UCB, Voyager Therapeutics, and the CHDI Foundation; license fee payments from the University of Pennsylvania for the QUIP and QUIP-RS; royalties from Wolters Kluweland; and fees for legal 
consultation for three lawsuits related to medication prescribing in patients with Parkinson's disease.

Jean Christophe Corvol: - reports grants from French Ministry of Health, Agence Nationale pour la Recherche, and INSERM; personal fees from BrainEver, personal fees from Theranexus, grants from Actelion, personal fees from BMS, personal fees from Zambon, personal fees from Pfizer, grants from Ipsen, personal fees from Abbvie, grants from Michael J Fox Foundation outside the submitted work.

Franck Durif - reports personal fees from Allergan, personal fees from Novartis, personal fees from Orkyn, personal fees from Lundbeck, personal fees from Teva, grants from the Ministry of Health, outside the submitted work. 


\section{ABSTRACT:}

Introduction: The management of impulse control disorders (ICDs) in Parkinson's disease (PD) relies on their early identification, allowing adjustment of antiparkinsonian treatment before these manifestations lead to major social, financial or legal consequences. The Questionnaire for Impulsive-Compulsive Disorders in Parkinson's Disease-Rating Scale (QUIP-RS) is an English-developed and -validated PDspecific rating scale constructed to support the rating of ICDs and related disorders and the assessment of changes in symptom severity over time, but it has not to date been validated in French.

Methods: We conducted an observational, multicenter, cross-sectional study among a subset of patients ( $n=280$ ) from the Drug Interacting with Genes in PD (DIG-PD) cohort, aiming to assess psychometric properties of the French version of QUIP-RS: acceptability, internal consistency, factor analysis, reproductibility and hypotheses testing. In addition to this scale, the following measures were applied: MDS-Unified Parkinson's Disease Rating Scale, Mini-Mental State Examination, Frontal Assessment Behavior, and Ardouin Scale of Behavior in Parkinson's Disease (ASBPD).

Results: Cronbach's alpha coefficient was 0.72 and ranged from 0.25 to 0.55 . Regarding test-retest reliability and inter-rater reliability, the Lin concordance coefficient for items was higher than 0.58. The correlations between QUIP-RS and ASBPD were moderate to high except for dopaminergic addiction and hobbyism $(r=0.41$ and 0.40 respectively, $p<0.001)$. No clinically significant correlation was found between QUIP-RS total score (and items) and other scales. 
Conclusion: The French version of the QUIP-RS appears to be a valid, reliable, and precise instrument for the assessment of ICDs and related disorders in PD. 


\section{INTRODUCTION}

Impulse control disorders (ICDs) and related behaviours are common in Parkinson's disease (PD) under chronic dopaminergic treatment, with a prevalence ranging from $14 \%$ to $43 \%{ }^{1-4}$ The main ICDs are pathological gambling, compulsive shopping or eating, and sexual behaviors. ${ }^{5}$ ICD-related behaviors include excessive hobbyism, punding and overuse of dopaminergic agents, also known as dopamine dysregulation syndrome..$^{5-7}$

The strongest risk factor for the emergence of ICDs in PD is the long-term use of dopaminergic therapy, with the strongest association reported for dopamine agonists (DAs). ${ }^{8-10}$ Other risk factors include younger age at PD onset, male sex, being single, past or current depression, positive family history of nicotine dependence or substance abuse, and sleep disorders such as RBD and RLS. ${ }^{6,7}$

Although the reversibility of ICDs and related behaviors after withdrawal of DAs has been documented in several studies, ${ }^{4,8,11}$ yet not consistently, ${ }^{12}$ ICDs and related behaviors may lead to serious financial, legal, or psychosocial consequences, and ideally should be prevented or identified as early as possible in order to modify dopaminergic therapy prior to the appearance of severe psycho-behavioral complications.

The Questionnaire for Impulsive-Compulsive Disorders in Parkinson's Disease (QUIP) has been designed for the diagnosis and screening of ICDs in PD, ${ }^{13}$ but does not allow to assess the severity of these symptoms and its evolution. The Questionnaire for Impulsive-Compulsive Disorders in Parkinson's Disease-Rating Scale (QUIP-RS) ${ }^{14}$ is an English-developed and -validated PD-specific rating scale developed to support the 
rating and follow up of ICDs and related disorders, allowing the monitoring of changes in symptom severity over time. It has been validated against various diagnostic ICD criteria. The QUIP-RS has good interrater and retest reliability, and responsiveness to change has been evaluated. The QUIP-RS has also been validated in German. ${ }^{15}$

The aim of this study was to validate the French version of the QUIP-RS a French cohort of PD patients, using The Ardouin Scale of Behavior in Parkinson's disease (ASBPD), ${ }^{16}$ a semi-structured interview assessing the severity of neuropsychiatric disorders in PD, as the gold standard. This scale has been recently validated in French, English, and Spanish and shows satisfactory metric properties. ${ }^{16,17}$

\section{METHODS}

\section{Design}

We conducted an observational, multicenter, cross-sectional study with retest.

\section{Participants}

\section{Subjects and methods}

\section{Subjects}

The Drug Interacting with Genes in PD (DIG-PD) study is an ongoing cohort study of PD patients, consecutively recruited between 5/2009-7/2013 in four French University hospitals and four General Hospitals. Eligible participants were PD patients (UKPDSBB criteria) with five years or less of disease duration at recruitment. Exclusion criteria were: age < 18 years old, and inability to read, understand, or answer written questionnaires. Patients diagnosed with atypical parkinsonism were excluded. 
Following the baseline visit, patients are followed annually for up to 6 years and complete interviews with a movement disorder expert.

For the present QUIP-RS validation study, we analysed data from the baseline visit to evaluate the instrument's psychometric properties. Sample size estimation was determined according to COSMIN guidelines.

The DIGPD study was funded by the French Ministry of Health (grant PHRC AOR0810), and sponsored by Assistance Publique Hôpitaux de Paris. The protocol was approved by the ethical committee of the Pitié-Salpêtrière University Hospital (France). All participants gave written informed consent. The study received ethical approval and was registered on the clinicaltrials.gov website (NCT01564992).

\section{Assessments}

In addition to sociodemographic characteristics, the following assessments were available: MDS-Unified Parkinson's Disease Rating Scale (MDS-UPDRS), ${ }^{18}$ Hoehn and Yahr scale (H\&Y), Mini-Mental State Examination (MMSE), ${ }^{19}$ Frontal Assessment Battery $(F A B),{ }^{20}$ Starktstein apathy scale, ${ }^{21}$ Hospital Anxiety and Depression Scale (HADS), ${ }^{22}$ ASBPD, ${ }^{16}$ and QUIP-RS. ${ }^{14}$ Dopaminergic treatments were calculated as levodopa equivalent daily dose, LEDD. ${ }^{23}$

The ASBPD assesses neuropsychiatric disorders in PD and consists of 21 items grouped into three parts: hypodopaminergic symptoms (anxiety, depression, apathy, irritability), non-motor fluctuations and hyperdopaminergic behavior (hypomanic mood, psychotic symptoms, nocturnal activity, diurnal somnolence, risk-taking behavior, excess motivation, compulsive eating and shopping, pathological gambling, 
hypersexuality, hobbyism, punding, dopaminergic addiction). Each item is rated on a five-point scale (severe disorder, 4; marked disorder, 3; moderate disorder, 2;

mild disorder, 1; absence of disorder, 0), Scores for hypodopaminergic disorders range from 0 to 20, for non-motor fluctuations from 0 to 8 and for hyperdopaminergic disorders from 0 to 56 . The total ASBPD score ranges from 0 to 84 .

The QUIP-RS assesses the frequency and severity of 4 ICDs (compulsive gambling, buying, eating, sexual behavior) and 3 related disorders (medication use, punding, hobbyism). The scale uses 4 questions for each disorder: 1- commonly reported thoughts, 2- urges/desires, 3- difficulty to control behaviors, and 4- behaviors associated with ICDs. For each question, it uses a 5-point Likert scale (score 0-4). Scores for each ICD and related disorder range from 0 to 16 , with a higher score indicating greater severity (i.e., frequency) of symptoms. The total QUIP-RS score for all ICDs and related disorders combined ranges from 0 to 112, and the ICDs-only score ranges from 0 to 64. The scale was translated in French by a bilingual psychologist. It was revised by two other persons with knowledge of French and expertise in rating scales and questionnaires. The French version was then back translated from French to English, and a final consensus regarding the two English versions (native and translated from French) was reached between the three professionals.

\section{Procedure}

Patients were clinically assessed in each center by movement disorders neurologists certified for MDS-UPDRS administration. Cognitive (MMSE, FAB) and behavioral (ASBPD, QUIP-RS) scales were administered in-person on the same day by a 
psychologist at each center. All psychologists participated in a telephone training session to standardize instructions for the administration of the ASPBD and QUIP-RS. Only patients, and not caregivers or partners, were interviewed. Patients were evaluated under their usual treatment, and patients with fluctuations were assessed in the "On" state. To evaluate inter-rater reliability, 53 consecutive patients were tested by 2 different psychologists, with an interval of 0 to 2 days between the 2 assessments. For both tools, the patients were interviewed and not the caregivers, precluding any bias due to different sources. Also, ASPBD and QUI-RS have not been developed to be addressed to the caregiver.

\section{Statistical analysis}

We used standard methods for the validation of rating scales. ${ }^{24}$ In addition to descriptive statistics, the following psychometric properties of the QUIP-RS scale were examined using Stata (version 13 StataCorp, College Station, US): (i) Acceptability: Data quality was considered satisfactory if more than $95 \%$ of the scale data were fully computable. Score range, closeness of mean to median, floor and ceiling effects, and skewness of score distributions were also analyzed. (ii) Internal consistency was determined through Cronbach's alpha coefficient (minimum accepted value: 0.70 ), the item homogeneity coefficient (criterion value: $\geq 0.30$ ), and the item-total and item-rest correlation corrected for overlap (criterion value: $\geq 0.30$ ). (iii) An exploratory factor analysis (principal components analysis with varimax rotation) was carried out to determine the scale structure. The number of factors was chosen according to usual recommendations: Kaiser criteria, plot of eigenvalues, and part of variance expressed 
by principal components. (iv) Reproductibility: the Lin's concordance coefficient was used to determine the test-retest reliability of the QUIP-RS scale. Values $\geq 0.70$ were deemed satisfactory. ${ }^{25}$ (v) Hypotheses testing: Regarding convergent validity, relationships between QUIP-RS scores, other quantitative measures of psychological disorders, and PD-related measures were studied using correlation coefficients (Pearson or Spearman, according to statistical distributions) ${ }^{26}$ External validity with respect to the ASBPD scale was explored using correlation coefficients when items of the ASBPD scale were considered as quantitative variables, and ANOVA or KruskalWallis tests when they were considered as categorical variables. Sensitive analysis was performed regarding partial coefficients correlation adjusted for age. Relationships between quantitative variables were assessed using Pearson or Spearman correlation coefficients (according to statistical distribution) and were represented graphically with a color-coded heatmap. 


\section{RESULTS}

Two hundred and eighty PD patients (58.5\% men) were included in this study; their characteristics are shown in Table 1 . Mean age was $64.3 \pm 9.9$ years and average duration of disease was $6.1 \pm 2.1$ years. Median H\&Y was 2.0 (IQR: 2.0-2.5) and mean (SD) MDS-UPDRS part III score was 23.9 (10.7).

Results for data quality and acceptability of the QUIP-RS and ASBPD scales are displayed in Suppl. Table 1 and Suppl. Table 2. Fully computable data were obtained for $100 \%$ of the patients. The mean (SD) total score of QUIP-RS was $5.12(7.90)$, with a minimum value of 0 and a maximum of 40 .

According to recommended cut-offs, ${ }^{14} 12.5 \%(n=35)$ of the patients had ICDs (score $\geq 10$ ). Eating behavior was the most frequent symptom ( $9.3 \%$ of patients, $n=26$, QUIPRS eating subscore score $\geq 7$ ) whereas compulsive buying was present in 1 patient only (QUIP-RS item buying subscore $\geq 8$ ).

\section{Internal consistency and exploratory factor analysis}

Table 2 displays results for the internal consistency of the QUIP-RS scale. Cronbach's alpha coefficient was 0.72 . The item-rest correlation for the scale as a whole ranged from 0.25 (pathological gambling) to 0.55 (compulsive buying), and inter-item correlations (Figure 1) were comprised between 0.04 (pathological gambling, punding) and 0.43 (compulsive buying).

The principal components analysis forced the number of factors to two and explained $55 \%$ of the variance (inertia/information). The most consistent factors were coincident 
with eating behavior, hobbism, punding, and compulsive buying (factor 1) and hypersexuality, dopaminergic addiction, and pathological gambling (factor 2).

\section{Test-retest and inter-rater reliability}

Test-retest reliability was determined in 53 patients (Table 2). The Lin concordance coefficient was higher than $0.58(95 \% \mathrm{Cl}=0.40 ; 0.76)$ for all items. For the total QUIP-RS score, it was $0.85(95 \% \mathrm{Cl}=0.77 ; 0.93)$, and $0.91(95 \% \mathrm{Cl}=0.87 ; 0.95)$ for ICDs total score.

\section{Construct validity}

The correlations between QUIP-RS and ASBPD were high for all items except dopaminergic addiction and hobbyism and moderate for these two items ( $r=0.41$ and 0.40 respectively, $p<0.001$ ) (Table 3 ). These results were confirmed when ASBPD was considered as a categorical variable. For example, the coefficient between QUIP-RS and ASBPD pathological gambling item considered as a continuous variable was 0.57 $(p<0.001)$. The mean (SD) value of the QUIP-RS pathological gambling item was 0.09 (0.43) in patients with a score of 0 for the corresponding ASBPD item ( $n=267), 4.33$ (3.94) for those with an ASBPD score of $1(n=9)$, and 6.00 (3.61) for those with an ASBPD score of $2(n=3)(p<0.001)$. For dopaminergic addiction, patients with a score at 0 for ASBPD dopaminergic addiction item $(n=267)$ had $0.23 \pm 0.88$ for QUIP-RS dopaminergic addiction item, those with an ASBPD score at $1(n=11)$ had $2.36 \pm 2.16$, and those with an ASBPD score at $2(n=2) 3.00 \pm 4.24(p<0.001)$. For hobbyism, patients with a score at 0 for ASBPD item $(n=248)$ had $0.83 \pm 1.86$ for QUIP-RS, those 
with an ASBPD score at $1(n=28)$ had $2.54 \pm 2.44$, those with an ASBPD score at 2 $(n=12) 4.67 \pm 3.96$, and with an ASBPD score at $3(n=1)$ had $7.00(p<0.001)$.

According to rules-of-thumb ( $r<0.3$ : no correlation; 0.3 to 0.5 : week correlation; $r>0.5$ : moderate to good correlation), no clinically significant correlation was found between the QUIP-RS total score (and items) and others scales: MDS-UPDRS ( $r=-0.18)$, Hoehn \& Yahr $(r=-0.25)$, MMSE $(r=0.04)$, FAB $(r=0.14)$, HADS-Anxiety $(r=0.19)$ and HADSDepression $(r=0.16)$, Starkstein apathy scale $(r=0.05)$ (Figure 1, Suppl. Table 3). Yet, there was a correlation between the subitem 1.6 of MDS-UPDRS (referring to ICDs and DDS) and QUIP-RS total score $(r=0.47(p<0.001))$ as well as with the QUIP-RS items referring to ICDs $(r=0.50(p<0.001)$. We found no correlation between the items 4.1 and 4.2 of MDS-UPDRS (referring to dyskinesia duration and impact) neither for QUIPRS total score $(r=0.04(p=0.59)$ and $r=0.09(p=0.15))$ nor for QUIP-RS items referring to $\operatorname{ICDs}(r=0.06(p=0.33)$ and $r=0.08(p=0.20))$.

Our results did not change after sensitivity analysis regarding partial coefficients correlation adjusted for age (data not shown).

\section{DISCUSSION}

According to this study, the French version of the QUIP-RS appears to be a valid, reliable, and precise instrument for the assessment of ICDs and related disorders in patients with PD.

To date, there are only a few validated tools to assess ICDs and related disorders in PD. However, such tools are essential as patients may not spontaneously report ICDs because they do not make the link between these disorders, PD and antiparkinsonian 
treatment, or due to an embarrassment to talk about these symptoms. Questioning the patient's partner is also often decisive to know if the patient presents with ICDs and related behaviors, providing crucial collateral information. It is necessary to have scales allowing both to diagnose ICDs and related disorders, and to follow their change under dopaminergic treatment or other interventions.

The Minnesota Impulsive Disorder Interview (MIDI) is a semi-structured interview used to assess the degree of impulsivity related to compulsive behavior. Neither the internal consistency of the items, nor the inter-reliability of the diagnoses made according to this tool have been demonstrated. The validity of the MIDI has been reported in a sample of patients with various psychiatric disorders but not in PD. ${ }^{27}$

The SCOPA-PC is a validated screening instrument for psychiatric complications in PD, ${ }^{28}$ including seven questions related to symptoms over the last month. Together with the QUIP questionnaire, the SCOPA-PC is until now the only validated tool for screening ICDs in PD. However, these questionnaires aim at diagnosing psychiatric complications and ICDs but are not a tool for the follow up as they do not allow to rate severity.

The ASBPD scale assesses neuropsychiatric disorders in PD: hypodopaminergic disorders, mood fluctuations according to the motor status, and hyperdopaminergic disorders including items referring to ICDs and related behaviors. This scale has been validated in several languages and shows good to excellent metric properties. This scale is thus valuable for follow up but it is relatively long to complete ( 1 hour on average) and thus is indicated primarily for research studies.

The QUIP-RS has been developed for the follow-up of ICDs and related disorders in PD and appears to be a valid and reliable rating scale. Cut-offs for the diagnosis of all 4 
ICDs (but not for DDS) have been proposed with a sensitivity and specificity $>80 \%$. The QUIP-RS can be self- or rater-administered and have been translated and validated in English and German. The main advantages of this scale are that it can be used for selfreport and that it can be completed in 5 minutes.

The acceptability of the French version QUIP-RS was excellent. A floor effect was observed because a large proportion of patients did not experience high scores on each items of ICDs and related disorders, and no patient obtained the highest score showing that in this population only few patients had severe ICDs and related disorders. This was also shown by the fact only $12.5 \%$ of patients reach the recommended cutoff for presence of any ICD. ${ }^{14}$

Internal consistency parameters met the standard criteria. From the inter-items correlations, we observed that variables are positively correlated, even if the strength of relationships was low to moderate. These results were confirmed by factor analysis highlighting principally two principal components: eating behavior, hobbyism, punding and compulsive buying (factor 1 ) and hypersexuality, dopaminergic addiction and pathological gambling (factor 2), with a moderate proportion of variance explained by this two factors. This could be explained by the low number of patients having a significant disorder using the recommended cutoff. ${ }^{14}$

The reproducibility was excellent apart for the item "dopaminergic addiction", where the retest reliability was 0.58 . Such a low reliability regarding the item "dopaminergic addiction" was also reported when validating the English version of the QUIP-RS. This could be due to the formulation of the query related to this item on the first (common thoughts) and second (urges/desires) dimension. Indeed, patients who have regular 
thoughts or preoccupations regarding their treatment, in order to avoid memory lapse, may answer "yes" to this item without any real compulsive behavior, increasing the risk of false positive. On the other hand, patients with a real compulsive use of their dopaminergic treatment may answer "no" to the question as identifying compulsive dopaminergic overuse with a self-reported questionnaire has been reported to be a high challenge. ${ }^{29}$ Indeed patients frequently underestimate the efficacy of their dopamine replacement therapy and argue that a new dose is actually necessary because of the negative reinforcement of aversive OFF non-motor symptoms combined with the risk of dopamine agonist withdrawal syndrome (DAWS), increasing the risk of false negative. ${ }^{29}$ Moreover, alexithymia has been reported to be more frequent in DDS PD patients, which may help explain why they minimize the medication abuse compared to what caregivers reported. ${ }^{30}$ Therefore, a trained instructor with a large clinical assessment may be needed to properly detect DDS. Otherwise, a screening tool fulfilled by a caregiver could provide a better estimation of dopamine medication overuse.

The external validity was good as a high level of association was observed between the items of QUIP-RS and the ASBPD scale for the same constructs. By contrast, low associations with scales measuring other constructs were noticed. This confirmed the specificity of the QUIP-RS in assessing the behavioral disorders.

In light of these results, we propose that the French version of the QUIP-RS is a comprehensive, valid, reliable, and precise instrument for the assessment of ICDs and related behaviors in Parkinson's disease. 


\section{REFERENCES}

1 Antonini A, Siri C, Santangelo G, Cilia R, Poletti M, Canesi M et al. Impulsivity and compulsivity in drug-naïve patients with Parkinson's disease. Mov Disord Off $J$ Mov Disord Soc 2011; 26: 464-468.

2 Weintraub D, Koester J, Potenza MN, Siderowf AD, Stacy M, Voon V et al. Impulse control disorders in Parkinson disease: a cross-sectional study of 3090 patients. Arch Neurol 2010; 67: 589-595.

3 Bastiaens J, Dorfman BJ, Christos PJ, Nirenberg MJ. Prospective cohort study of impulse control disorders in Parkinson's disease. Mov Disord Off J Mov Disord Soc 2013; 28: 327-333.

4 Corvol J-C, Artaud F, Cormier-Dequaire F, Rascol O, Durif F, Derkinderen P et al. Longitudinal analysis of impulse control disorders in Parkinson disease. Neurology 2018; 91: e189-e201.

5 Voon V, Fox SH. Medication-related impulse control and repetitive behaviors in Parkinson disease. Arch Neurol 2007; 64: 1089-1096.

6 Voon V, Sohr M, Lang AE, Potenza MN, Siderowf AD, Whetteckey J et al. Impulse control disorders in Parkinson disease: a multicenter case--control study. Ann Neurol 2011; 69: 986-996.

7 Vitale C, Santangelo G, Trojano L, Verde F, Rocco M, Grossi D et al. 
Comparative neuropsychological profile of pathological gambling, hypersexuality, and compulsive eating in Parkinson's disease. Mov Disord Off J Mov Disord Soc 2011; 26: $830-836$.

8 Weintraub D, Siderowf AD, Potenza MN, Goveas J, Morales KH, Duda JE et al. Association of dopamine agonist use with impulse control disorders in Parkinson disease. Arch Neurol 2006; 63: 969-973.

9 Lee J-Y, Kim J-M, Kim JW, Cho J, Lee WY, Kim H-J et al. Association between the dose of dopaminergic medication and the behavioral disturbances in Parkinson disease. Parkinsonism Relat Disord 2010; 16: 202-207.

10 Maréchal E, Denoiseux B, Thys E, Crosiers D, Pickut B, Cras P. Impulse control disorders in Parkinson's disease: an overview from neurobiology to treatment. J Neurol 2015; 262: 7-20.

11 Mamikonyan E, Siderowf AD, Duda JE, Potenza MN, Horn S, Stern MB et al. Long-term follow-up of impulse control disorders in Parkinson's disease. Mov Disord Off J Mov Disord Soc 2008; 23: 75-80.

12 Siri C, Cilia R, Reali E, Pozzi B, Cereda E, Colombo A et al. Long-term cognitive follow-up of Parkinson's disease patients with impulse control disorders. Mov Disord Off J Mov Disord Soc 2015; 30: 696-704.

13 Weintraub D, Hoops S, Shea JA, Lyons KE, Pahwa R, Driver-Dunckley ED et al. Validation of the questionnaire for impulsive-compulsive disorders in Parkinson's disease. Mov Disord 2009; 24: 1461-1467.

14 Weintraub D, Mamikonyan E, Papay K, Shea JA, Xie SX, Siderowf A. Questionnaire for impulsive-compulsive disorders in Parkinson's Disease-Rating Scale. Mov Disord 2012; 27: 242-247.

15 Probst CC, Winter LM, Möller B, Weber H, Weintraub D, Witt K et al. 
Validation of the questionnaire for impulsive-compulsive disorders in Parkinson's disease (QUIP) and the QUIP-rating scale in a German speaking sample. J Neurol 2014; 261: 936-942.

16 Rieu I, Martinez-Martin P, Pereira B, De Chazeron I, Verhagen Metman L, Jahanshahi M et al. International validation of a behavioral scale in Parkinson's disease without dementia. Mov Disord Off J Mov Disord Soc 2015; 30: 705-713.

17 Ardouin C, Chéreau I, Llorca P-M, Lhommée E, Durif F, Pollak P et al. [Assessment of hyper- and hypodopaminergic behaviors in Parkinson's disease]. Rev Neurol (Paris) 2009; 165: 845-856.

18 Movement Disorder Society Task Force on Rating Scales for Parkinson's Disease. The Unified Parkinson's Disease Rating Scale (UPDRS): status and recommendations. Mov Disord Off J Mov Disord Soc 2003; 18: 738-750.

19 Folstein MF, Folstein SE, McHugh PR. 'Mini-mental state'. A practical method for grading the cognitive state of patients for the clinician. J Psychiatr Res 1975; 12: $189-198$.

20 Dubois B, Slachevsky A, Litvan I, Pillon B. The FAB: a Frontal Assessment Battery at bedside. Neurology 2000; 55: 1621-1626.

21 Starkstein SE, Mayberg HS, Preziosi TJ, Andrezejewski P, Leiguarda R, Robinson RG. Reliability, validity, and clinical correlates of apathy in Parkinson's disease. J Neuropsychiatry Clin Neurosci 1992; 4: 134-139.

22 Zigmond AS, Snaith RP. The hospital anxiety and depression scale. Acta Psychiatr Scand 1983; 67: 361-370.

23 Tomlinson CL, Stowe R, Patel S, Rick C, Gray R, Clarke CE. Systematic review of levodopa dose equivalency reporting in Parkinson's disease. Mov Disord Off J Mov Disord Soc 2010; 25: 2649-2653. 
24 Terwee CB, Bot SDM, de Boer MR, van der Windt DAWM, Knol DL, Dekker J et al. Quality criteria were proposed for measurement properties of health status questionnaires. J Clin Epidemiol 2007; 60: 34-42.

25 Landis JR, Koch GG. The measurement of observer agreement for categorical data. Biometrics 1977; 33: 159-174.

26 Fitzpatrick R, Davey C, Buxton MJ, Jones DR. Evaluating patient-based outcome measures for use in clinical trials. Health Technol Assess Winch Engl 1998; 2: i-iv, 1-74.

27 Grant JE, Levine L, Kim D, Potenza MN. Impulse Control Disorders in ADult Psychiatric Inpatients. Am J Psychol 2005; : 2184-2188.

28 Visser M, Verbaan D, van Rooden SM, Stiggelbout AM, Marinus J, van Hilten JJ. Assessment of psychiatric complications in Parkinson's disease: The SCOPA-PC. Mov Disord Off J Mov Disord Soc 2007; 22: 2221-2228.

29 Warren N, O’Gorman C, Lehn A, Siskind D. Dopamine dysregulation syndrome in Parkinson's disease: a systematic review of published cases. J Neurol Neurosurg Psychiatry 2017; 88: 1060-1064.

30 Baumann-Vogel H, Valko PO, Eisele G, Baumann CR. Impulse control disorders in Parkinson's disease: don't set your mind at rest by self-assessments. Eur $J$ Neurol 2015; 22: 603-609. 


\section{FIGURE CAPTIONS:}

Figure 1. Heatmap representation of correlation coefficients between the QUIP-RS total score (and items) and others scales

Correlation coefficients (Spearman $r$ ) are color-coded as shown on the Horizontal bar on top of the figure. ICD: Impulse control disorders; DDS: dopamine dysregulation syndrome; MDS-UPDRS: Movement Disorders Society Unified Parkinson Disease Rating Scale; H\&Y: Hoehn and Yahr scale; MMSE: Mini-Mental State Examination; FAB: Frontal assessment battery; HADS: Hospital Anxiety and Depression Scale. 

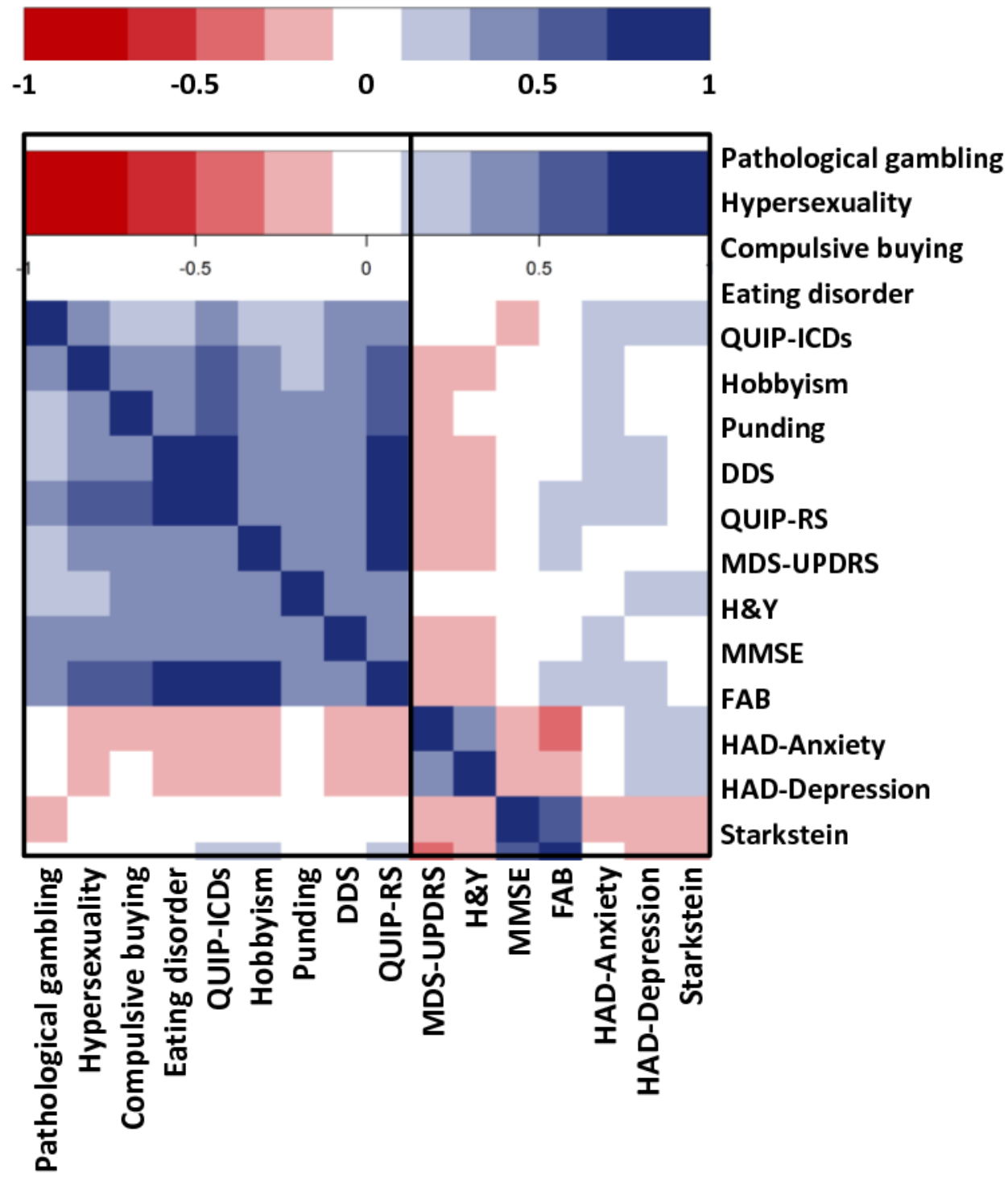
Table 1: Demographical and clinical characteristics of study participants $(n=280)$

\begin{tabular}{lc}
\hline Characteristics & \% or mean \pm SD \\
\hline Gender, male & $58.4 \%$ \\
Age (years) & $64.3 \pm 9.9$ \\
Duration of disease (years) & $6.1 \pm 2.1$ \\
MDS-UPDRS & $23.9 \pm 10.7$ \\
Hoehn and Yahr & $2.2 \pm 0.5$ \\
Levodopa (LED) (mg/day) & $355.6(270.5)$ \\
DA (LED)(mg/day) & $192.8(103.2)$ \\
Treatment TOTAL LED (mg/day) & $518.7(305.4)$ \\
\hline MMSE & $28.1 \pm 2.8$ \\
FAB & $16.5 \pm 2.1$ \\
HADS (anxiety) & $6.9 \pm 3.6$ \\
HADS (depression) & $5.3 \pm 3.4$ \\
Starkstein apathy scale & $12.1 \pm 5.7$ \\
\hline
\end{tabular}

MDS-UPDRS: Movement Disorders Society-Unified Parkinson Disease Rating Scale; LED: Levodopa equivalent dose; DA: dopamine agonists; TOTAL LED: Total levodopa equivalent dose including all antiparkinsonian drugs; MMSE: Mini-Mental State Examination; FAB: Frontal Assessment Battery; HADS: Hospital Anxiety and Depression Scale. 
Table 2: QUIP-RS internal consistency and Test-Retest reliability

\begin{tabular}{|c|c|c|c|c|c|}
\hline & $\begin{array}{l}\text { Item-total } \\
\text { correlation }\end{array}$ & $\begin{array}{l}\text { Item-rest } \\
\text { correlation }\end{array}$ & $\begin{array}{c}\text { Average } \\
\text { inter-item } \\
\text { correlation }\end{array}$ & Cronbach & $\begin{array}{l}\text { Reproducibility } \\
\text { Lin concordance } \\
\text { coefficient }\end{array}$ \\
\hline Pathological gambling & 0.47 & 0.25 & 0.31 & 0.73 & $0.87[0.82 ; 0.92]$ \\
\hline Hypersexuality & 0.66 & 0.49 & 0.25 & 0.67 & $0.91[0.87 ; 0.96]$ \\
\hline Compulsive buying & 0.70 & 0.55 & 0.24 & 0.66 & $0.83[0.76 ; 0.91]$ \\
\hline Eating disorder & 0.61 & 0.43 & 0.27 & 0.69 & $0.87[0.80 ; 0.94]$ \\
\hline Total ICDs & & & & & $0.91[0.87 ; 0.95]$ \\
\hline Hobbyism & 0.67 & 0.50 & 0.25 & 0.67 & $0.80[0.70 ; 0.90]$ \\
\hline Punding & 0.52 & 0.32 & 0.29 & 0.71 & $0.86[0.78 ; 0.93]$ \\
\hline DDS & 0.65 & 0.48 & 0.26 & 0.66 & $0.58[0.40 ; 0.76]$ \\
\hline Total QUIP-RS & & & & & $0.85[0.77 ; 0.93]$ \\
\hline
\end{tabular}

ICDs: Impulse control disorders, DDS: dopamine dysregulation syndrome 
Table 3: External validity in comparison to ASBPD scale

\begin{tabular}{|c|c|c|c|}
\hline & Correlation coefficient $^{1}$ & Mean $\pm S D(n)^{2}$ & p-value \\
\hline \multirow{4}{*}{ Pathological gambling } & \multirow{4}{*}{$0.57(p<0.001)$} & $0: 0.09 \pm 0.43(267)$ & \multirow{4}{*}{$p<0.001$} \\
\hline & & $1: 4.33 \pm 3.94(9)$ & \\
\hline & & $2: 6.00 \pm 3.61(3)$ & \\
\hline & & $3: 12.0 \pm N E(1)$ & \\
\hline \multirow{4}{*}{ Hypersexuality } & \multirow{4}{*}{$0.70(p<0.001)$} & $0: 0.28 \pm 0.86(243)$ & \multirow{4}{*}{$p<0.001$} \\
\hline & & $1: 4.00 \pm 2.91(27)$ & \\
\hline & & $2: 6.75 \pm 3.06(8)$ & \\
\hline & & $3: 13.5 \pm 0.71(2)$ & \\
\hline \multirow{4}{*}{ Compulsive buying } & \multirow{4}{*}{$0.56(p<0.001)$} & $0: 0.25 \pm 0.91(262)$ & \multirow{4}{*}{$p<0.001$} \\
\hline & & $1: 3.25 \pm 2.24(16)$ & \\
\hline & & $2: 6.00 \pm N E(1)$ & \\
\hline & & 3: $9.00 \pm N E(1)$ & \\
\hline \multirow{4}{*}{ Eating disorder } & \multirow{4}{*}{$0.64(p<0.001)$} & $0: 0.47 \pm 1.38$ (186) & \multirow{4}{*}{$p<0.001$} \\
\hline & & 1: $2.46 \pm 2.52(71)$ & \\
\hline & & $2: 6.89 \pm 2.77(19)$ & \\
\hline & & $3: 9.25 \pm 3.50(4)$ & \\
\hline \multirow{4}{*}{ Hobbyism } & \multirow{4}{*}{$0.40(p<0.001)$} & $0: 0.83 \pm 1.86$ (239) & \multirow{4}{*}{$p<0.001$} \\
\hline & & $1: 2.54 \pm 2.44(28)$ & \\
\hline & & $2: 4.67 \pm 3.96(12)$ & \\
\hline & & $3: 7.00 \pm N E(1)$ & \\
\hline \multirow{4}{*}{ Punding } & \multirow{4}{*}{$0.61(p<0.001)$} & $0: 0.07 \pm 0.46(248)$ & \multirow{4}{*}{$p<0.001$} \\
\hline & & $1: 1.10 \pm 1.48(20)$ & \\
\hline & & $2: 4.50 \pm 4.20(10)$ & \\
\hline & & $3: 10.50 \pm 6.4(2)$ & \\
\hline \multirow{4}{*}{$\begin{array}{l}\text { Dopamine dysregulation } \\
\text { syndrome }\end{array}$} & \multirow{4}{*}{$0.41(p<0.001)$} & $0: 0.23 \pm 0.88(267)$ & \multirow{4}{*}{$p<0.001$} \\
\hline & & $1: 2.36 \pm 2.16(11)$ & \\
\hline & & $2: 3.00 \pm 4.24(2)$ & \\
\hline & & 3: NA & \\
\hline
\end{tabular}

${ }^{1}$ Correlation coefficient between QUIP-RS and ASBPD items (as a quantitative variables) ${ }^{2}$ Study of relation between QUIP-RS and ASBPD items (ASBPD as a categorical variable) ASBPD : Ardouin scale of behavior in Parkinson's disease ;. 